\title{
Ceratocystis fimbriata causando murcha em atemóia na região de Botucatu-SP
}

\author{
Ana Carolina Firmino ${ }^{1}$, Hugo José Tozze Júnior ${ }^{2}$, Paula Nepomuceno Costa ${ }^{3}$, Edson Luiz Furtado ${ }^{1}$
}

\begin{abstract}
${ }^{1}$ Departamento de Produção Vegetal, Defesa Fitossanitaria, UNESP/FCA, Botucatu-SP (Bolsista Fapesp e CNPq). ${ }^{2}$ Departamento de Fitopatologia e Nematologia, ESALQ/FCA, Piracicaba-SP. ${ }^{3}$ Departamento de Engenharia Florestal, UNESP/FCA, Botucatu-SP.

Autor para correspondência: Ana Carolina Firmino (anacarfir@gmail.com)

Data de chegada: 24/05/2012. Aceito para publicação em: 04/06/2012.
\end{abstract}

A atemóia é um híbrido Annona cherimola Mill. com $A$. squamosa L. e possui características importantes que são de interesse comercial, fazendo com que seu consumo esteja em franco crescimento. Atualmente, o principal mercado consumidor é o Estado de São Paulo, sendo que os frutos desta planta são destinados ao consumo in natura. Em 2009, na região de Botucatu/SP/Brasil, plantas de atemóia foram encontradas apresentando sintomas de murcha e seca. Estes sintomas normalmente são ocasionados por Ceratocystis spp. patógeno o qual vem causando problemas em muitas culturas de importância econômica. Esse fungo coloniza o sistema vascular (xilema), causando sintomas iniciais de perda de coloração das folhagens, murcha e, conseqüentemente, morte da planta. Fragmentos do caule de plantas com sintomas de seca foram coletados e colocados sobre isca de cenoura em câmara úmida e incubados a $25 \pm 2^{\circ} \mathrm{C}$ sob fotoperíodo alternado. Após formação de peritécio, uma porção de massa contendo ascósporos foi transferida para meio MEA (Malte, extrato de levedura e agar) para formação de colônias, sendo incubado nas condições anteriores. Após 10 dias, observou-se na colônia a presença de peritécio escuro, globoso (tamanho médio de $208,40 \mu \mathrm{m}$ x $230,15 \mu \mathrm{m}$ ) e com rostro longo (tamanho médio de $942 \mu \mathrm{m}$ ). Os ascósporos apresentavam

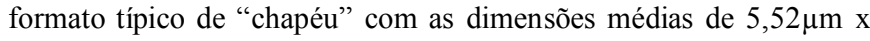
$4,28 \mu \mathrm{m}$. Em relação às estruturas assexuadas foram observados aleuroconídios (tamanho médio de $10,20 \mu \mathrm{m} \times 13,66 \mu \mathrm{m}$ ) e

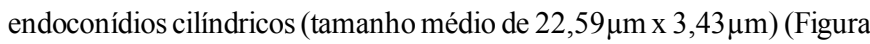
1). Não foram observados endoconídios doliformes. As características morfológicas indicam que o isolado do fungo obtido pertence à espécie Ceratocystis fimbriata. A região ITS-5.8S rDNAdo do isolado foi seqüenciada e essa apresentou $98 \%$ de similaridade com seqüências de um isolado de C. fimbriata CMW14797 (AY953382.1) do GenBankNCBI. A inoculação do isolado nas plantas foi realizada com disco de meio MEA, colonizado pelo fungo $(1 \mathrm{~cm})$, com 10 dias de crescimento. $\mathrm{O}$ disco foi introduzido em um ferimento realizado no caule (15 cm acima do solo) de planta atemóia sadias com seis meses de idade. O local da inoculação foi envolvido por um algodão (umedecidos com água destilada esterilizada) e com filme plástico. Plantas também foram inoculadas somente com um disco de meio MEA, sem estar colonizado pelo fungo, como testemunha. As plantas inoculadas foram mantidas em casa-de-vegetação, com temperatura média de $28^{\circ} \mathrm{C}$. O sintoma de murcha causado por $C$. fimbriata foi observado 90 dias após inoculação e a morte das plantas 120 dias. O fungo foi isolado, novamente, do caule de atemóia com sintomas no meio MEA, confirmando ser ele o agente causal da doença. Assim, este é o primeiro relato de C. fimbriata em atemóia na região de Botucatu-SP-Brasil.

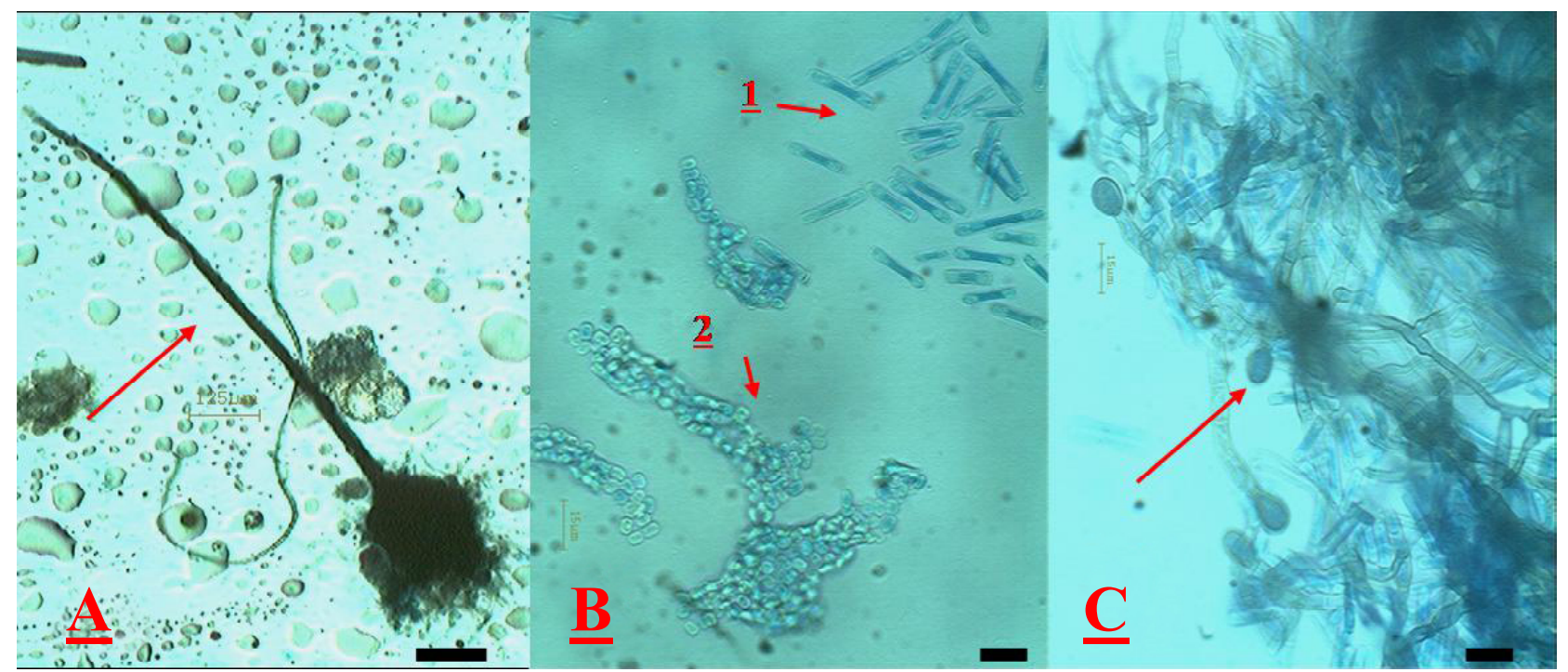

Figura 1: Fungo Ceratocystis isolado de atemóia. (A) Peritécio; (B1) Endoconídio cilíndrico; (B2) Ascósporos; (C) Aleuroconídio. (Barras: A=125 بm; B e $\mathrm{C}=15 \mu \mathrm{m})$ 